Bul. Agrohorti 4 (1) :1 - 8 (2016)

\title{
Budi Daya Buah Naga Putih (Hylocereus undatus) di Sleman, Yogyakarta : Panen dan Pascapanen
}

\section{Dragon Fruit (Hylocereus undatus) Cultivation in Sleman, Yogyakarta : Harvest and Posharvest}

\author{
Oktiadewi Kristriandiny dan Slamet Susanto* \\ Departemen Agronomi dan Hortikultura, Fakultas Pertanian, Institut Pertanian Bogor \\ (Bogor Agricultural University), Jl. Meranti, Kampus IPB Darmaga, Bogor 16680, Indonesia \\ Telp.\&Faks. 62-251-8629353 e-mail agrohort.ipb.ac.id \\ *Penulis untuk korespondensi: ssanto@cbn.net
}

Disetujui 18 Januari 2016/Published online 25 Januari 2016

\begin{abstract}
Management aspect of dragon fruit cultivation and the harvest and postharvest handling was evaluated. The research was conducted at Sabila Farm, Sleman, Yogyakarta in February-June 2013. The results showed that Sabila Farm could produce dragon fruit with great quality, therefore the dragon fruits from Sabila Farm are competitive with other farmers. Harvesting system was conducted based on the order of consumers and the purposes of agritourism. Dragon fruit harvesting by the labours was carried out manually based on the characteristics of fruits. The labours in Sabila Farm had good skills for harvesting, therefore the loss of harvest due to the mechanical damage almost zero. The yield losses that occured in Sabila Farm was caused by birds and chickens. Rainfall pattern affected the production of dragon fruit and the total of dragon fruit flowers based on correlation and regression analysis, inferred two months before flowering time. Although postharvest handling in Sabila Farm had conducted properly, however grading and packaging needed some improvenments.
\end{abstract}

Keywords: cultivation, dragon fruit, harvest, postharvest

\section{ABSTRAK}

Aspek panen dan pascapanen buah naga putih penting untuk diketahui. Kegiatan penelitian dilaksanakan di Sabila Farm, Sleman, Yogyakarta pada bulan Februari-Juni 2013. Hasil menunjukkan bahwa budi daya buah naga putih yang diterapkan di Sabila Farm secara keseluruhan sudah cukup baik sehingga dapat menghasilkan mutu buah yang mampu bersaing dengan perusahaan lain. Panen tidak dilaksanakan secara serempak setiap bulan, tetapi berdasarkan pesanan konsumen dan keperluan agrowisata. Pemanenan buah naga putih oleh tenaga kerja dilakukan secara manual sesuai dengan karakteristik umur panen. Tenaga kerja panen memiliki keterampilan yang cukup baik sehingga kerusakan hasil panen akibat kerusakan mekanis jarang terjadi. Kerusakan hasil panen disebabkan oleh hama burung dan ayam. Berdasarkan uji korelasi dan regresi, produktivitas dan jumlah bunga dipengaruhi oleh curah hujan dua bulan sebelumnya. Pengelolaan pascapanen buah naga putih di Sabila Farm secara keseluruhan sudah cukup baik, tetapi grading dan pengemasan masih perlu perbaikan.

Kata kunci: buah naga, budi daya, panen, pascapanen 


\section{PENDAHULUAN}

Buah naga atau dragon fruit merupakan salah satu komoditas hortikultura yang belum lama dikenal, dibudidayakan, dan diusahakan di Indonesia. Tanaman buah naga yang awalnya dikenal sebagai tanaman hias ini sudah cukup lama dikenal masyarakat Taiwan, Vietnam, maupun Thailand. Buah naga termasuk dalam famili Cactacea dengan karakteristik memiliki duri pada setiap ruas batangnya. Hylocereus undatus merupakan jenis buah naga yang lebih dulu dikenal oleh masyarakat Indonesia (Kristanto, 2010). Komoditas buah naga dalam pengembangan agribisnis mempunyai prospek yang cerah untuk peluang ekspor dan pasarnya masih terbuka lebar serta memiliki potensi yang sangat baik untuk pasar di dalam negeri (Chusna, 2011).

Djamila et al. (2010) mengemukakan bahwa kegiatan budi daya buah naga di Indonesia sangat menguntungkan karena disamping memberi keuntungan secara ekonomi pada petani, hal ini juga akan mengurangi impor buah, bahkan ada kemungkinan untuk menembus pasar ekspor. Tahun 2006, total produksi buah naga dari perkebunan di Malang, Yogyakarta, Semarang, Pasuruan, Jombang dan Klaten sebesar 1341 ton/tahun. Produksi buah naga terus meningkat seiring dengan meningkatnya permintaan konsumen.

Tujuan kegiatan adalah mempelajari dan menganalisis aspek panen dan pascapanen di lahan budi daya buah naga dalam rangka perbaikan kualitas.

\section{BAHAN DAN METODE}

Kegiatan dilaksanakan di Sabila Farm, Sleman, Yogyakarta selama 4 bulan, mulai Februari sampai Juni 2013.

Pelaksanaan kegiatan mengikuti alur kerja di kebun selama 4 bulan dengan pembagian kerja sesuai dengan tingkatan struktur organisasi. Metode pengumpulan data terdiri atas data primer dan sekunder. Data primer merupakan hasil pengamatan kegiatan budi daya buah naga secara keseluruhan di lapangan terutama pada aspek panen yang meliputi sistem panen, karakteristik umur panen, tenaga kerja panen, pengaruh curah hujan terhadap produktivitas dan jumlah bunga buah naga putih, serta kerusakan hasil panen, sedangkan pada aspek pascapanen yaitu meliputi pengkelasan dan pengemasan. Data sekunder diperoleh dari data perusahaan yang dengan cara wawancara dan diskusi dengan pihak perusahaan untuk mendukung pelaksanaan teknis lapangan, antara lain letak wilayah administratif, keadaan tanah dan iklim, luas areal dan tata guna lahan, keadaan tanaman dan produksi, serta struktur organisasi dan ketenagakerjaan.

Analisis yang dilakukan terhadap data yang diperoleh dari kegiatan magang adalah analisis secara deskriptif dan kuantitatif. Pengolahan data dilakukan dengan menggunakan rataan, persentase, uji korelasi dan analisis regresi. Uji korelasi pada taraf 5\% digunakan untuk mengetahui hubungan antara curah hujan dengan produksi dan jumlah bunga buah naga putih, sedangkan analisis regresi digunakan untuk mengetahui besarnya pengaruh curah hujan terhadap produktivitas dan jumlah bunga buah naga putih.

\section{HASIL DAN PEMBAHASAN}

\section{Budi daya}

Pembibitan buah naga putih dilakukan secara vegetatif, yaitu dengan stek batang atau sulur. Pembibitan dilakukan langsung di lapangan dengan cara memotong sulur-sulur tua (minimal berumur 2 tahun) dan produktif (sudah pernah berbuah). Sulur yang telah didapat dipotong dengan ukuran $30-35 \mathrm{~cm}$. Bagian ujung bawah stek dibuat meruncing untuk merangsang dan mempermudah pertumbuhan akar serta sebagai penanda bagian yang akan ditanam ke dalam tanah. Selanjutnya stek dikeringanginkan selama 2-3 minggu untuk mengeringkan luka bekas potongan. Setelah dikeringkan, bahan stek siap ditanam ke lahan.

Alat dan bahan yang digunakan dalam penanaman buah naga meliputi cangkul, linggis, tali rafia, meteran, 4 buah stek batang dan tiang panjatan. Tiang panjatan ini dapat berupa beton dan kayu tanaman hidup. Jarak tanam yang diterapkan adalah $2.5 \mathrm{~m} \times 2.5 \mathrm{~m}$. Media tanam yang diperlukan untuk menanam buah naga antara lain adalah pupuk kandang dengan dosis 10-12 $\mathrm{kg}$, kapur dolomit $2 \mathrm{~kg}$, pupuk NPK $50 \mathrm{~g}$ dan sekam bakar $1-2 \mathrm{~kg}$.

Pemupukan menggunakan dua jenis pupuk, yaitu pupuk organik dan anorganik. Aplikasi pupuk NPK, kapur dolomit dan sekam bakar dilakukan pada saat awal penanaman buah naga. Pupuk kandang diaplikasikan pada saat awal penanaman dan pemupukan lanjutan dilakukan secara berkala yaitu setiap 4 bulan setelah penanaman dengan menggunakan pupuk kandang dosis $10-20 \mathrm{~kg}$. Waktu yang baik untuk aplikasi 
pemupukan adalah pada bulan April, Agustus dan Desember.

Pengikatan cabang sulur dilakukan pada cabang yang tumbuh di sulur utama atau sulur primer agar pertumbuhannya teratur ke atas hingga mencapai ujung tiang panjatan. Setiap pertambahan ketinggian sekitar $30 \mathrm{~cm}$ dilakukan pengikatan cabang menggunakan tali rafia. Ikatan dapat dilepas apabila akar epifit pada sulur telah tumbuh merambat dan kuat pada tiang panjatan. Setelah sulur-sulur utama tanaman buah naga mencapai ujung tiang dan bercabang, selanjutnya dilakukan pengaturan letak cabang sulur yang bertujuan mengarahkan pertumbuhan pertumbuhan tanaman menjadi normal dan membentuk kanopi yang baik.

Pemangkasan pada buah naga memiliki empat kriteria. Kriteria pertama dilakukan pada cabang yang tumbuh dari cabang utama atau primer. Kriteria kedua dilakukan pada cabang yang sudah tidak produktif lagi, atau biasa disebut siwing. Kriteria ketiga adalah cabang yang telah berumur lebih dari dua tahun, dan kriteria keempat adalah sulur-sulur yang terhalang mendapatkan sinar matahari.

Pengendalian gulma meliputi tiga cara, yaitu manual, mekanis, dan kimiawi. Pengendalian dengan cara manual dilakukan dengan menggunakan cangkul dan tangan. Pengendalian dengan cara mekanis dilakukan dengan menggunakan mesin pemotong rumput. Pengendalian dengan cara kimiawi dilakukan dengan menggunakan bahan kimia, yaitu herbisida dengan bahan aktif Isopropilamin glifosat dengan merk dagang Roundup 486 SL. Konsentrasi herbisida yang digunakan yaitu $0.167 \%$.

Jenis hama yang menyerang tanaman buah naga adalah bekicot (Achatina fulica), burung dan ayam (Gallus gallus). Bekicot atau Achatina fulica menyerang tunas-tunas muda calon cabang buah naga. Pengendalian bekicot dilakukan dengan membuang semua bekicot yang berada di tanaman dan sekitar tanaman secara manual. Sanitasi kebun perlu dilakukan untuk menjaga kebersihan kebun, sehingga kehadiran hama dapat dicegah.

Jenis penyakit yang menyerang tanaman buah naga adalah busuk lunak batang yang disebabkan oleh Phytophthora sp. Gejala serangan busuk lunak batang ditandai dengan sulur yang berair dan busuk berwarna coklat. Penyakit busuk lunak batang dapat menyerang sulur di bagian tengah, pangkal maupun ujung sulur. Penanggulangan penyakit busuk lunak batang di Sabila Farm dilakukan dengan eradikasi atau pemotongan batang yang berpenyakit secara tuntas, sehingga penyebaran penyakit pada tanaman yang sehat disekitarnya dapat dicegah.

Buah naga yang diberikan perlakuan pembungkusan biasa dilakukan pada buah yang letaknya agak ke bawah untuk melindungi buah dari patokan ayam. Kegiatan ini dilakukan pada buah yang sudah mulai matang dengan warna kulit yang mulai merah dengan menggunakan pembungkus buah berjaring-jaring kecil atau polynet dengan bahan sejenis acrylic atau plastik.

\section{Panen dan Pasca Panen}

Pemanenan buah naga dilakukan dengan cara manual. Alat panen yang digunakan antara lain keranjang buah, angkong, sarung tangan, gunting pangkas dan kendaraan roda tiga terbuka. Buah yang siap panen digenggam menggunakan tangan kemudian dipotong pada tangkai tanpa merusak sulur tempat buah tersebut tumbuh.

Sortasi buah naga dilakukan secara visual berdasarkan tampilan fisik (warna dan bentuk). Buah naga yang baik atau layak jual memiliki warna kulit buah dan jumbai sesuai karakteristik panen serta kulit buah yang mulus. Buah naga yang tidak layak jual memiliki kondisi kulit yang luka, memar, bolong dan busuk.

Pembersihan buah naga hasil panen yang dilakukan adalah dengan menggunakan kuas dan gunting pangkas. Kuas digunakan untuk membersihkan kotoran-kotoran seperti tanah atau debu, sedangkan gunting pangkas digunakan untuk membuang bagian sulur yang masih menempel pada pangkal buah naga.

Pengkelasan adalah kegiatan menyeleksi dan memisahkan buah berdasarkan ukuran buah. Pengkelasan buah naga putih yang dilakukan menjadi empat kelas, yaitu kelas Super, kelas A, kelas B dan kelas C. Kelas Super merupakan kelas buah naga putih yang memiliki bobot $>700 \mathrm{~g}$, sedangkan kelas A adalah kelas buah naga putih yang memiliki bobot antara 600-700 g. Buah naga putih kelas B memiliki bobot antara 500-600 $\mathrm{g}$ dan buah naga putih kelas $\mathrm{C}$ memiliki bobot antara 400-500 g.

Label yang digunakan adalah label kertas tempel berbentuk bulat kecil dengan cap perusahaan. Perusahaan menggunakan kemasan kotak kardus bersekat dengan logo. Kotak kardus ini berkapasitas $5 \mathrm{~kg}$, sedangkan bobot kardusnya sendiri $0.5 \mathrm{~kg}$. Ukuran kardus sebesar $32 \mathrm{~cm} \times 32$ $\mathrm{cm}$ dengan tinggi $16 \mathrm{~cm}$. Kardus harus dilubangi setiap sisinya sebanyak 4 lubang sebagai sirkulasi 
udara, sehingga total lubang pada setiap satu kardus adalah 16 lubang.

Pengangkutan buah naga hasil menggunakan angkong atau kendaraan roda tiga terbuka dalam pengangkutan buah dari lapang ke rumah pascapanen, sedangkan pengangkutan buah untuk distribusi dilakukan dengan menggunakan kendaraan roda tiga tertutup.

\section{Agrowisata dan Pemasaran}

Kebun buah naga milik Sabila Farm memiliki empat fungsi, yaitu budi daya, produksi, edukasi dan rekreasi. Kegiatan agrowisata yang bersifat edukatif ini dapat dilakukan indoor dan outdoor yang diantaranya adalah wisata kebun dan petik buah naga sendiri, pelatihan budi daya buah naga, dan acara motivasi untuk bertani buah naga. Agrowisata yang disediakan oleh Sabila Farm juga bersifat fleksibel, artinya rangkaian dan jenis kegiatannya disesuaikan dengan keinginan pengunjung.

Kegiatan penjualan ini dilakukan setiap hari Jumat, mulai pukul 07.00-10.00 WIB di salah satu pasar lokal di Yogyakarta, yaitu Pasar Tani,
Dinas Pertanian Daerah Istimewa Yogyakarta (DIY).

\section{Sistem Panen}

Masa panen buah naga putih adalah 6 bulan, yaitu pada bulan November sampai Mei. Pemanenan tersebut tidak dilakukan secara serempak setiap bulannya, tetapi berdasarkan pesanan dari konsumen dan berdasarkan keperluan agrowisata. Konsumen memesan buah naga putih berdasarkan jumlah (kg) yang diinginkan. Buah naga putih akan dipanen pada waktu tertentu hingga jumlah beratnya mencapai jumlah bobot sesuai dengan pesanan, sehingga buah yang berada di kebun tidak dipanen sampai habis.

Buah naga mulai berbuah pada umur 1.5-2 tahun setelah tanam. Umur panen buah naga yang tepat adalah sekitar 53 hari. Bunga yang muncul mulai dari duri hingga mekar sekitar 20 hari, sedangkan mulai dari bunga mekar hingga menjadi buah yang siap petik adalah 33 hari. Masa panen buah naga yaitu 6 bulan dalam setahun, sedangkan umur produktif tanaman buah sekitar 20 tahun (Tabel 1).

Tabel 1. Masa panen dan fase pembungaan buah naga di Sabila Farm, Yogyakarta

\begin{tabular}{llllllllllllll}
\hline & Jan & Feb & Mar & Apr & Mei & Jun & Jul & Agust & Sept & Okt & Nov & Des \\
\hline Masa panen & & & & & & & & & & & & & \\
Fase pembungaan
\end{tabular}

Tenaga kerja panen membutuhkan keterampilan yang baik agar kualitas buah tetap terjaga mulai dari pemetikan buah hingga buah segar sampai ke tangan konsumen. (Tabel 2).

Tabel 2. Prestasi kerja panen buah naga putih

$$
\text { Periode panen ke- } \frac{\text { Prestasi kerja panen }(\mathrm{kg})}{\text { Penulis } \quad \text { Karyawan }}
$$

Periode panen ke-1 dilakukan pada bulan Februari, sedangkan periode panen ke-2 dan ke-3 dilakukan pada bulan Maret. Periode panen ke-4 dilakukan pada saat bulan April, sedangkan periode panen ke-5 dilakukan pada bulan Mei. Rata-rata prestasi kerja penulis dalam pemanenan buah naga putih (Tabel 2) yaitu sebesar $19.4 \mathrm{~kg}$, sedangkan rata-rata prestasi kerja panen karyawan sebesar 39.4 kg. Kitinoja dan Kader (2002) menyatakan bahwa pemanen atau pemetik secara

\begin{tabular}{crr}
1 & 50.0 & 110.0 \\
2 & 15.0 & 24.5 \\
3 & 14.0 & 25.0 \\
4 & 10.0 & 20.5 \\
5 & 7.6 & 17.0 \\
\hline Rata-rata & 19.4 & 39.4 \\
\hline
\end{tabular}

manual sebaiknya terlatih dengan baik sehingga dapat memanen dangan cara yang benar dalam upaya mengurangi kerusakan mekanis dan bahan yang tidak bermanfaat atau waste.

\section{Pengaruh Curah Hujan terhadap Produktivitas dan Jumlah Bunga}

Produktivitas buah dipengaruhi berbagai faktor lingkungan salah satunya adalah air. Berdasarkan Tabel 3 nilai korelasi antara curah hujan dengan produktivitas buah naga putih 
selama 4 tahun menunjukkan hasil sebesar 0.805 . Hal tersebut menunjukkan bahwa kedua faktor tersebut memiliki tingkat keeratan yang tinggi dan memiliki hubungan yang positif. Semakin tinggi curah hujan maka produktivitas buah naga akan semakin tinggi. Tabel 3 Hubungan curah hujan terhadap produktivitas buah naga putih.

Hasil analisis regresi pengaruh curah hujan terhadap produktivitas buah naga putih menunjukkan pola garis linear (Gambar 1). Persamaan regresi antara dua faktor tersebut adalah $\mathrm{y}=0.0359 \mathrm{x}+2$ 252.7. Berdasarkan hasil tersebut dapat dilihat bahwa setiap kenaikan curah hujan sebesar $1 \mathrm{~mm}$ dapat meningkatkan produktivitas buah naga sebesar $0.0359 \mathrm{~kg}$. Pengaruh curah hujan terhadap produksi ditunjukan dengan nilai determinasi (R2) sebesar 0.6476. Hal ini menunjukkan bahwa curah hujan mempengaruhi produktivitas buah naga putih yang menjadi buah sebesar $64.76 \%$.

Tabel 3. Hubungan curah hujan terhadap produktivitas buah naga putih

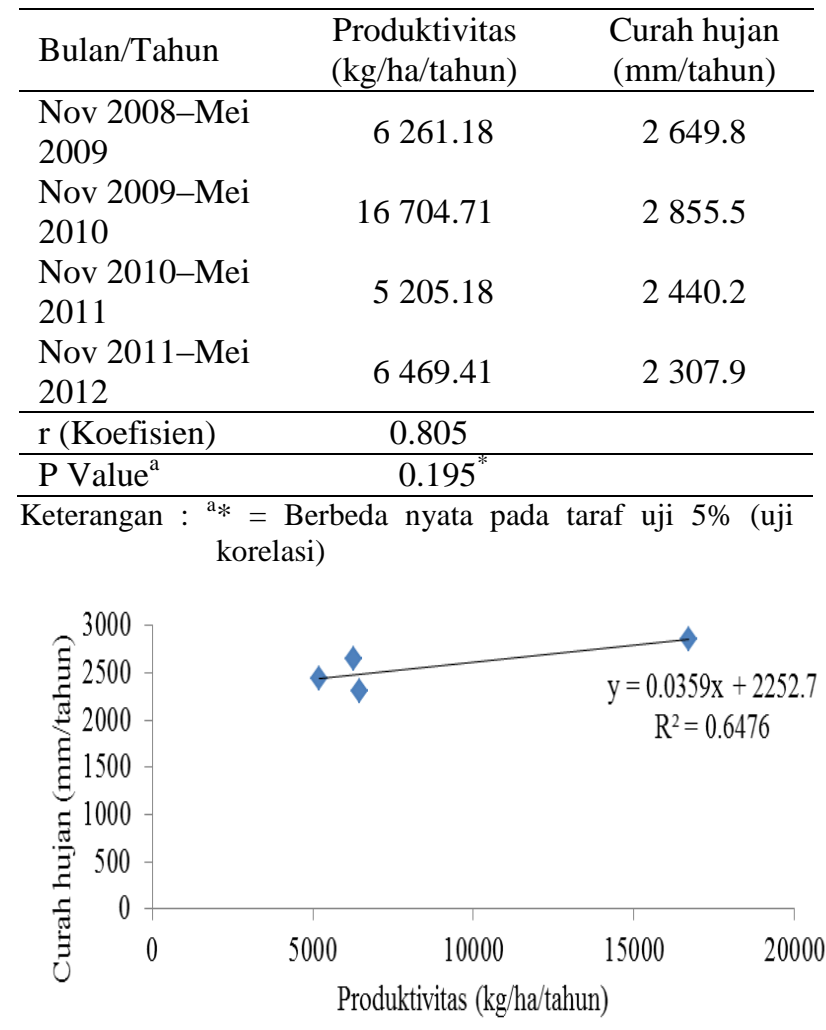

Gambar1. Pengaruh curah hujan terhadap produktivitas buah naga putih

Kebutuhan air atau efisiensi penggunaan air untuk setiap jenis tanaman sangat bervariasi. Erwiyono et al. (2009) menyatakan bahwa peran air pada metabolisme tanaman terkait ketersediaan air baik dalam hal volume maupun sebarannya, dapat berpengaruh nyata terhadap pertumbuhan dan produktivitas tanaman. Merten (2003) mengemukakan meskipun tanaman buah naga merupakan kaktus, tetapi tanaman ini menyerap air lebih banyak dibandingkan dengan jenis tanaman kaktus gurun lainnya. Buah naga adalah tanaman yang berasal dari areal yang memiliki curah hujan dan kelembaban yang tinggi. Air dalam jumlah yang sedikit setiap harinya untuk tanaman ini akan lebih bermanfaat dibandingkan dengan kekurangan air dalam jumlah yang banyak dan sering. Buah naga merupakan salah satu tanaman yang memiliki lintasan fotosintesis CAM (Crassulacean Acid Metabolism), sehingga sangat efisien dalam penggunaan air (Luders dan McMahon, 2006, Mizrahi et al., 2007).

\section{Jumlah Bunga yang Menjadi Buah}

Fase pembungaan buah naga dilokasi penelitian berlangsung pada bulan SeptemberMaret (Tabel 1) dan puncak pembungaan buah naga berlangsung pada bulan Desember-Februari (Sabila Farm, 2013). Hasil panen atau produksi Hylocereus undatus pada bulan Februari-Mei 2013 (Tabel 6) merupakan hasil pembentukan buah dari fase pembungaan pada bulan Desember 2012 sampai Maret 2013, karena mulai dari bakal buah hingga menjadi buah matang dibutuhkan waktu sekitar 53 hari. (Tabel 4, Gambar 2).

Tabel 4. Hubungan curah hujan terhadap jumlah bunga yang menjadi buah

\begin{tabular}{lrc}
\hline Bulan/tahun & $\begin{array}{c}\text { Jumlah bunga } \\
\text { (unit) }\end{array}$ & $\begin{array}{c}\text { Curah hujan } \\
\text { (mm/bulan) }\end{array}$ \\
\hline Desember/2012 & 14203 & 341 \\
Januari/2013 & 2668 & 560 \\
Februari/2013 & 953 & 472 \\
Maret/2013 & 180 & 354 \\
\hline r $\left(\right.$ Koefisien) $^{\text {P Value }}{ }^{\text {a }}$ & \multicolumn{3}{c}{-0.452} \\
\hline Sumer: & \multicolumn{3}{c}{$0.548^{\text {th }}$} \\
\hline
\end{tabular}

Sumber: Sabila Farm 2013, ${ }^{a}$ tn $=$ Tidak berbeda nyata pada taraf uji 5\% (uji korelasi)

Berdasarkan Tabel 5 nilai korelasi antara curah hujan dengan jumlah bunga selama 4 bulan (Desember 2012-Maret 2013) menunjukkan hasil sebesar 0.548. Hal ini menunjukkan bahwa kedua faktor tersebut memiliki tingkat keeratan yang rendah dan memiliki hubungan yang negatif. Semakin tinggi curah hujan maka jumlah bunga Hylocereus undatus akan semakin rendah.

Hasil analisis regresi pengaruh curah hujan terhadap jumlah bunga menunjukkan pola 
garis linear (Gambar 2). Persamaan regresi antara dua faktor tersebut adalah $y=-0.0072 x+464.37$. Berdasarkan hasil tersebut dapat dilihat bahwa setiap kenaikan curah hujan sebesar $1 \mathrm{~mm}$ dapat menurunkan jumlah bunga Hylocereus undatus sebesar 0.0072 unit. Pengaruh curah hujan terhadap jumlah bunga ditunjukan dengan nilai determinasi $\left(\mathrm{R}^{2}\right)$ sebesar 0.2053. Hal ini menunjukkan bahwa curah hujan pada bulan yang sama mempengaruhi jumlah bunga yang menjadi buah sebesar $20.53 \%$.

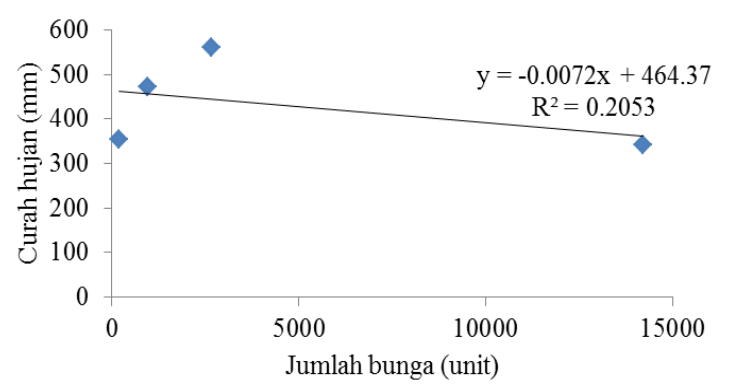

Gambar 2. Pengaruh curah hujan terhadap jumlah bunga yang menjadi buah

Tabel 5. Perbandingan pengaruh curah hujan terhadap jumlah bunga

\begin{tabular}{lcc}
\hline Pengaruh curah hujan & $Y$ & $\mathrm{R}^{2}$ \\
\hline 1 bulan sebelum & $-0.0022 x+466.04$ & 0.0250 \\
2 bulan sebelum & $-0.0275 x+485.41$ & 0.8173 \\
3 bulan sebelum & $-0.0252 x+334.98$ & 0.6187 \\
4 bulan sebelum & $-0.0177 x+216.04$ & 0.2932 \\
\hline
\end{tabular}

Tabel 5 menunjukkan perbandingan pengaruh curah hujan terhadap jumlah bunga yang menjadi buah pada bulan Desember 2012 sampai Maret 2013. Pada Tabel 5 dapat dilihat bahwa nilai determinasi $\left(R^{2}\right)$ yang paling tinggi terdapat pada curah hujan bulan September 2012 sampai Januari 2013 (2 bulan sebelumnya) yaitu sebesar 0.8173 dengan persamaan regresi $y=$ $0.0275 x+485.41$. Berdasarkan hasil tersebut dapat dilihat bahwa setiap kenaikan curah hujan sebesar $1 \mathrm{~mm}$ dapat menurunkan jumlah bunga
Hylocereus undatus sebesar 0.0275 unit. Curah hujan pada bulan-bulan tersebut juga mempengaruhi jumlah bunga yang menjadi buah pada bulan Desember 2012-Maret 2013 sebesar $81.73 \%$.

Intensitas curah hujan memberikan pengaruh langsung terhadap pembungaan buah naga. Pada tanaman buah naga, saat diferensasi kuncup bunga siap diinduksi menjadi bunga dapat berubah kembali menjadi kuncup vegetatif, apabila curah hujan tinggi dan intensistas radiasi matahari rendah. Curah hujan yang tinggi juga dapat menurunkan tingkat penyerbukan bunga (Tjasadihardja, 1987; Pasaribu, 2011). Hylocereus undatus merupakan tanaman hari panjang, sehingga membutuhkan panjang hari (fotoperiode) yang lebih lama untuk menginduksi pembungaan (Nerd et al, 2002; Luders dan McMahon, 2006). Jaya (2010) mengemukakan bahwa buah naga tersedia dalam jumlah yang besar di pasaran Indonesia selama bulan November sampai April. Hal tersebut diakibatkan karena pada periode tersebut tanaman buah naga menerima penyinaran atau radiasi matahari yang lebih lama dibanding dengan bulan-bulan lainnya.

\section{Kerusakan Hasil Panen}

Kerusakan hasil panen umumnya dibagi menjadi dua, yaitu kerusakan hasil di lapangan dan selama transportasi. Kerusakan hasil panen hanya terjadi di lapangan saja (Tabel 6). Persentase kerusakan hasil panen selama 4 bulan dari hasil pengamatan lapangan yaitu sebesar $15.11 \%$. Menurut Direktorat Budi daya Tanaman Buah (2009), jumlah buah yang tidak layak jual (reject) maksimal 10\% dari produksi lahan. Penyebab dari kerusakan hasil panen di lapangan di lokasi studi adalah karena serangan hama. Serangan hama tersebut antara lain buah yang rusak karena dimakan oleh hama burung dan ayam yang memiliki gejala yang hampir sama yaitu terdapat lubang-lubang berbentuk patukan paruh berdiameter sekitar 2-3 cm.

Tabel 6. Hasil panen dan kerusakan hasil panen buah naga putih

\begin{tabular}{lccc}
\hline Bulan & Hasil panen $(\mathrm{kg})$ & Kerusakan hasil panen $(\mathrm{kg})$ & Persentase kerusakan hasil panen $(\%)$ \\
\hline Februari & 7890.36 & 1310.20 & 16.60 \\
Maret & 1482.00 & 125.00 & 8.43 \\
April & 529.44 & 68.00 & 12.84 \\
Mei & 99.91 & 8.49 & 8.50 \\
\hline Jumlah & 10001.71 & 1511.69 & 15.11 \\
\hline
\end{tabular}




\section{Pengkelasan dan Pengemasan}

Grading bertujuan untuk memberikan nilai lebih (harga yang lebih tinggi) untuk kualitas yang lebih baik. Setyabudi (2003) mengemukakan bahwa grading merupakan pengelompokan buah hasil panen berdasarkan kriteria yang telah disepakati oleh produsen dan konsumen. Grading yang dilakukan pada bulan Februari-Mei 2013 dapat dilihat pada Tabel 7.

Tabel 7. Pengkelasan (grading) buah naga putih

\begin{tabular}{lcc}
\hline $\begin{array}{l}\text { Kelas } \\
\text { (grade })\end{array}$ & Hasil panen(kg) & Persentase (\%) \\
\hline Super & 1746.10 & 17.46 \\
A & 4170.74 & 41.70 \\
B & 2064.53 & 20.64 \\
C & 2020.34 & 20.20 \\
\hline Jumlah & 10001.71 & 100.00 \\
\hline
\end{tabular}

Kelas Super merupakan kelas buah naga putih yang memiliki bobot $>700 \mathrm{~g}$, sedangkan kelas A adalah kelas buah naga putih yang memiliki bobot antara 600-700 g. Buah naga putih kelas B memiliki bobot antara 500-600 g dan buah naga putih kelas $\mathrm{C}$ memiliki bobot antara 400-500 g. Buah naga putih kelas Super yang dihasilkan Sabila Farm 10-20\% dari produksi, kelas A 40-50\% dari produksi, dan kelas B dan C 20-30\% dari produksi (Sabila Farm, 2013).

Grading buah naga putih yang dilakukan di Sabila Farm sudah mendekati standar apabila dibandingkan dengan CODEX STAN 237-2003 (standar internasional untuk buah naga). CODEX menggunakan 9 jenis kelas dalam grading buah naga putih berdasarkan ukuran buah. Kelas ini disebut dengan size code (kode ukuran). Terdapat 4 kode ukuran yang rentangnya hampir sama dengan rentang ukuran yang digunakan di Sabila Farm, yaitu Kode F, Kode G, Kode H dan Kode I. Kode F memiliki rentang ukuran 401-500 g, Kode $\mathrm{G}$ memiliki rentang ukuran 501-600 g, Kode $\mathrm{H}$ memiliki rentang ukuran $601-700 \mathrm{~g}$, dan Kode I memiliki rentang ukuran > $701 \mathrm{~g}$. Setyabudi (2003) menyatakan bahwa pedagang buah sentra-sentra produksi di Indonesia telah melakukan pemilahan atau grading namun pengelompokannya masih beragam, baik pemberian tanda (notasi) maupun dasar pengelompokan buah ditandai dengan notasi angka (1, 2 dan 3) dan huruf (A, B, dan C) berdasarkan ukuran dan jumlah buah dalam satuan bobot. Hal tersebut mengharuskan adanya standar acuan untuk memperoleh pengemasan buah naga putih menggunakan kemasan kotak kardus berkapasitas $5 \mathrm{~kg}$ dengan sekat sebagai pembatas buah di dalam kardus yang berfungsi untuk menjaga agar buah tidak saling bergesekan selama distribusi berlangsung. Jumlah buah yang dapat masuk ke dalam kardus dengan menggunakan sekat adalah 9 buah, sedangkan jika sekat tidak digunakan maka jumlah buah yang dapat masuk ke dalam kardus adalah 10-11 buah tergantung dari ukuran buah tersebut. Kitinoja dan Kader (2002) mengemukakan bahwa penambahan lembaran sekat sebagai pemisah dalam kotak karton kemasan akan menambah kekuatan tumpukan serta mencegah gesekan antar buah saat penanganan dan transportasi.

\section{KESIMPULAN}

Budi daya buah naga putih yang diterapkan sudah cukup baik sehingga dapat menghasilkan mutu buah yang mampu bersaing dengan perusahaan lain. Sistem panen yang dilakukan berdasarkan pesanan konsumen dan keperluan agrowisata. Pemanenan buah naga putih oleh tenaga kerja dilakukan secara visual sesuai dengan karakteristik umur panen. Tenaga kerja panen memiliki keterampilan yang cukup baik sehingga kehilangan hasil panen akibat kerusakan mekanis jarang terjadi. Kerusakan hasil panen masih terjadi di disebabkan oleh hama seperti tikus, burung dan ayam. Jumlah bunga dipengaruhi oleh curah hujan, yakni curah hujan dua bulan sebelumnya. Oleh karena itu, mengetahui curah hujan 2 bulan sebelum pembungaan penting untuk manajemen panen buah naga.

\section{DAFTAR PUSTAKA}

Chusna, C.B. 2011. Peluang Bisnis Buah Naga di Indonesia [Internet]. [diunduh 2013 Mei 7]. Tersedia pada: http://research.amikom. ac.id/index.php/KIM/article/view/4384/271 8

Direktorat Budi Daya Tanaman Buah. 2009. Pedoman Baku Budi Daya (Standard Operating Procedure/SOP) Buah Naga (Hylocereus undatus) Kabupaten Sleman. Departemen Pertanian, Jakarta. 
Djamila, S., Budiastra, I.W., Sutrisno. 2010. Ultrasound Wave Transmission Characteristics and Its Relationships with Physico-Chemical of Dragon Fruit [Internet]. [diunduh 2012 Okt 18]. Tersedia pada:http://repository.ipb.ac.id/bitstream/ha ndle/123456789/54337/PERTETA\%20PU RWOKERTO\%204\%202010.pdf?sequence $=1$.

Erwiyono, R., R.Y. Yacob dan Usmadi. 2009. Pengaruh pola curah hujan terhadap produksi kopi: studi di satu perkebunan di Banyuwangi. Agrotropika 14(1):29-36.

Kristanto, D. 2010. Buah Naga, Pembudi dayaan di Pot dan di Kebun. Cetakan IV (Edisi Revisi). Jakarta (ID): Penebar Swadaya.

Luders, L., McMahon, G. 2006. The pitaya or dragon fruit (Hylocereus undatus). Agnote D42:1-4.

Merten, S. 2003. A review of Hylocereus production in the United States. J. PACD. 5:98-105.
Mizrahi, Y., Raveh, E., Yossov, E., Nerd, A., Ben-Asher, J. 2007. New fruit crops with high water use efficiency. In: Janick J, Whipkey A, editor. Issues in new crops and new uses. Alexandri: ASHA Press. p $216-$ 222.

Nerd, A., Sitrit, Y., Kaushik, R,A., Mizrahi, Y. 2002. High summer temperatures inhibit flowering in vine pitaya crops (Hylocereus spp.). Scientia Horticulturae 96(2002):343350.

Pasaribu, D.W. 2011. Pengaruh $\mathrm{GA}_{3}$ terhadap pembentukan bunga dan buah tanaman buah naga merah (Hylocereus costaricensis (Web.) Britton \& Rose. [skripsi]. Padang (ID): Universitas Andalas.

Setyabudi, D,A. 2003. Bangsal penanganan pascapanen buah. Di dalam: Broto W, editor. Teknologi Penanganan Pascapanen Buah untuk Pasar [Internet]. [diunduh 2012 Jul 5]. Tersedia pada: www.pascapanen.litbang.deptan. go.id/assets/...juknis_buah.pdf

Tsajadihardja, A. 1987. Hubungan antara pertumbuhan pucuk, perkembangan buah serta tingkat kandungan asam indol asetat di dalam biji dan layu pentil kakao (Theobroma cacao L.) [disertasi]. Bogor (ID): Institut Pertanian Bogor. 